\title{
A Fault Diagnosis Method of Power Systems Based on Gray System Theory
}

\author{
Huang Darong, Tang Jianping, and Zhao Ling \\ College of Information Science and Engineering, Chongqing Jiaotong University, Chongqing 400074, China \\ Correspondence should be addressed to Huang Darong; hcx1978@163.com
}

Received 22 August 2014; Revised 9 November 2014; Accepted 13 November 2014

Academic Editor: XiaoSheng Si

Copyright ( 2015 Huang Darong et al. This is an open access article distributed under the Creative Commons Attribution License, which permits unrestricted use, distribution, and reproduction in any medium, provided the original work is properly cited.

\begin{abstract}
To provide some decision-making suggestions for fault diagnosis in power systems, a new model for identifying fault component is constructed by using Gray theory. Firstly, the basic concepts of Gray theory are introduced and explained in detail. And then the recognition algorithm of the power supply interrupted districts and the assignment principle of fault state vectors are depicted according to the working principle of protective relays (PRs) and circuit breakers (CBs). Secondly, based on the concept of the Gray correlation degree, the fault information explanation degree model is constructed and the judging method of malfunction and rejection for PRs and CBs is established. Meanwhile, to achieve the goal of the fault diagnosis, the fault diagnosis procedure that determined which components malfunction is designed for power systems. Finally, some simple experiments have already verified that the proposed method and model are effective and reasonable and the trend of further research is analyzed and summarized.
\end{abstract}

\section{Introduction}

Fault diagnosis of power systems is a method, which uses the information collected from protective relays and circuit breaker to recognize fault component and malfunctioned or tripped PRs and CBs. It is generally known that the fault component recognition is the crucial problem in engineering application [1]. In recent year, many fault diagnosis methods of power systems are proposed, including expert system [2], artificial neural network [3], optimization technology [4], rough set theory $[5,6]$, Petri net [7], and Bayesian network [6]. In order to meet certain preconditions in the existing diagnosis methods, some assumptions are made for them. But in some cases these assumptions may be contrary to reality and may even cause error diagnosis results. For example, when the information of protective device is incomplete, the fault diagnosis' conclusion may be incorrect. So the crucial difficulty of fault diagnosis is how to guarantee the corrective and effective diagnosis results for power systems with incomplete information [8]. In other words, if we want to get the corrective and effective diagnosis results, we have to know how to obtain the unknown information by utilizing the known information under the condition of incomplete information [9-11].

Fortunately, the Gray system theory can simulate and determine the unknown information according to the known information of systems. In addition, using the Gray systems theory to construct the fault diagnosis model involves a smaller sample and little information. The process is easier to be operated. However, the anomalies contrary to qualitative analysis will not be produced in the process of Gray correlation analysis. Hence, under the condition of information incomplete and not explicit, the Gray system theory has its unique superiority; that is, it is an effective method in case of incomplete and uncertain information.

Based on the above, application of the Gray theory to the fault diagnosis of power systems is proposed in this paper. The layout of the rest of the paper is arranged as follows. in Section 2 the Gray system theory and Gray correlation analysis were introduced briefly. Section 3 described the fault diagnosis method and model of power systems based on Gray system theory and designed the diagnostic procedure for fault 
components. In Section 4 we have discussed the simulative results by experiments. Finally, Section 5 concluded this paper with inferences and directions for future work.

\section{Basis Introduction of Gray System Theory and Gray Correlation Analysis}

2.1. Basal Principle of Gray System Theory. Gray system theory, which is established by Chinese scholar Professor Deng Ju-Long in 1982, has been used to research uncertain problem with lack of data and information. In general speaking, some information is known and other pieces of information are unknown in uncertain data systems. The main idea of Gray system theory is to describe correctly the systems' evolution law and to monitor effectively their running behavior by extracting valuable information from the known information. Over forty years later, the structure system of Gray system theory has basically taken shape. The theoretical basis includes Gray Matrix, Gray Algebra, and Gray Equation. And the Gray model (GM) may also implement the analysis, evaluation, prediction, and control decision of uncertain data systems by using spatial association rule and sequence generation method. For future understanding of the advantages of Gray system theory, six basic principles are introduced as follows.

2.1.1. Differential Information Principle. There is the difference among differential information. In other words, the difference is the information. For example, if there are two differential objects or systems, everyone has unique information that is not similar to another piece of information. One of the most basic pieces of information which the human society perceives is that the world comes from the difference between matter and matter.

2.1.2. Nonuniqueness of Solutions. The solution is nonunique under the condition of information being incomplete and vague. The uncertainty of systems leads to the existence of uncertain information and then causes nonuniqueness of solutions.

2.1.3. Smallest Information Principle. The basic idea of Gray system theory is to utilize the smallest information achieving from known knowledge data to accomplish a given task. The smallest information getting by researching the uncertain problem with the small samples and poor information is the fundamental basis of making a distinction between Gray area and no-Gray.

\subsubsection{Cognitive Foundation Principle}

The Foundation of Cognition Is Information. The accurate and complete cognition is determined according to definite and precise knowledge; the uncertain and incomplete knowledge may also lead to vague cognition. Correspondingly, if there is no information of systems, the cognition of systems is not also completed. Thus the cognition should be studied based on information.
2.1.5. Innovation Priority Principle. The function of new information is more important than old information for cognitive behaviors, because the new information directly reflects the current states of the system and mainly influences the future trend of the development.

2.1.6. Gray Indestructibility Principle. Notably, the incomplete and uncertain information is very much strongly entrenched in real systems. As new information is continuously generated in real engineering, the cognition conclusion is improved gradually and the level of cognition will tend to rationality and correctness. Accordingly, the Gray systems do not disappear.

Based on the above principles, the theoretical model implementing a given task may be constructed according to small sample and poor information. However, the running states and trend of systems are determined by many factors in real application. So we need to discern the primary factors and lesser factors. And fortunately, the Gray correlation analysis, which is the important part of Gray system theory, can judge the connection in accordance with the approximation degree of the two-dimensional curve in time domain and frequencies domain. The higher the similarity is, the greater the correlation is. For further analysis, the Gray relational axioms are introduced firstly.

2.2. Gray Correlation Axiom. Suppose that the behavior sequence of the system is $X_{0}=\left(x_{0}(1), x_{0}(2), \ldots, x_{0}(n)\right)$; thus the corresponding factor series is as follows:

$$
\begin{aligned}
X_{1} & =\left(x_{1}(1), x_{1}(2), \ldots, x_{1}(n)\right), \\
& \vdots \\
X_{i} & =\left(x_{i}(1), x_{i}(2), \ldots, x_{i}(n)\right), \\
& \vdots \\
X_{m} & =\left(x_{m}(1), x_{m}(2), \ldots, x_{m}(n)\right) .
\end{aligned}
$$

For a given real $r\left(x_{0}(k), x_{i}(k)\right)$, if $r\left(X_{0}, X_{i}\right)=$ $(1 / n) \sum_{k=1}^{n} r\left(x_{0}(k), x_{i}(k)\right)$ satisfies

(1) normalization: $0<r\left(X_{0}, X_{i}\right) \leq 1$, and $X_{0}=X_{i} \Rightarrow$ $r\left(X_{0}, X_{i}\right)=1$;

(2) integrity: let $X_{i}, X_{j} \in X=\left\{X_{s} \mid s=0,1, \ldots, m, m \geq\right.$ $2\}$; if $i \neq j$, then $r\left(X_{i}, X_{j}\right) \neq r\left(X_{j}, X_{i}\right)$.

(3) even symmetry: if $X=\left\{X_{i}, X_{j}\right\}, X=\left\{X_{i}, X_{j}\right\} \Leftrightarrow$ $r\left(X_{i}, X_{j}\right)=r\left(X_{j}, X_{i}\right)$

(4) accessibility: the value of the Euclid distance $\left|x_{0}(k)-x_{i}(k)\right|$ is inversely proportional to the value of the given real $r\left(x_{0}(k), x_{i}(k)\right)$.

Thus $r\left(X_{0}, X_{i}\right)=(1 / n) \sum_{k=1}^{n} r\left(x_{0}(k), x_{i}(k)\right)$ is called as Gray relational degree, where $r\left(X_{0}, X_{i}\right)$ represents the correlation coefficient of each pair of variables $X_{i}$ and $X_{j}$. Four conditions (1-4) are also regarded as Gray relational four axioms. 
Notice that four conditions just do positively mean these things. Normalization illustrates that there is a correlation between two arbitrary behavior sequences. Integrity describes that the Gray relational degree is influenced by the external environment. If the outside environment is changed, the relational degree is also varied. So the symmetry principle is not necessarily true. Meanwhile, even symmetry represents that the symmetry principle is true while the set of factors contains just two factors. Accessibility may constrain the relational quantization.

2.3. Gray Correlation Analysis. To get the computing formula of Gray related degree, the distance measure between vectors $x_{0}(k)$ and $x_{i}(k)$ is defined as follows:

$$
\Delta_{0 i k}=\left\|x_{0}(k)-x_{i}(k)\right\| .
$$

And suppose that

$$
\begin{aligned}
& \Delta_{\max }=\max _{i} \max _{k} \Delta_{0 i k}, \\
& \Delta_{\min }=\min _{i} \min _{k} \Delta_{0 i k} .
\end{aligned}
$$

According to the formulas (2)-(3), the correlation coefficient between vectors $x_{0}(k)$ and vector $x_{i}(k)$ is defined as follows:

$$
r\left(x_{0}(k), x_{i}(k)\right)=\frac{\Delta_{\min }+\xi \Delta_{\max }}{\Delta_{\min }+\xi \Delta_{\max }}
$$

that is,

$$
\begin{aligned}
& r\left(x_{0}(k), x_{i}(k)\right) \\
& =\frac{\min _{i} \min _{k}\left|x_{0}(k)-x_{i}(k)\right|+\xi \max _{i} \max _{k}\left|x_{0}(k)-x_{i}(k)\right|}{\left|x_{0}(k)-x_{i}(k)\right|+\xi \max _{i} \max _{k}\left|x_{0}(k)-x_{i}(k)\right|},
\end{aligned}
$$

where $\xi$ is called the resolution coefficients and the values of $\xi$ are usually restricted to a certain range $(0,1)$.

Notice that the discriminatory power varies depending on the different correlation coefficients: the smaller the $\xi$ is, the higher the differences between two correlation coefficients are and the stronger the discriminatory power is.

Let $r\left(x_{0}(k), x_{i}(k)\right)=r_{0 i}(k)$, and then we define

$$
r\left(X_{0}, X_{i}\right)=\frac{1}{n} \sum_{k=1}^{n} r\left(x_{0}(k), x_{i}(k)\right)=\frac{1}{n} \sum_{k=1}^{n} r_{0 i}(k),
$$

and $r\left(X_{0}, X_{i}\right)$ is considered as the Gray correlation degree between reference sequence $X_{0}$ and compare sequence $X_{i}$. Obviously, $r\left(X_{0}, X_{i}\right)$ satisfy Gray relational four axioms (1-4).

2.4. Computing Algorithm of Gray Correlation Degree. By the definition of Gray correlation degree, the computational steps of Gray correlation are made as follows.
(1) Collect the evaluation data on the evaluation index system; then the sequences of data may be stated in matrix form as follows:

$$
\left(X_{0}, X_{1}, \ldots, X_{m}\right)=\left(\begin{array}{cccc}
x_{0}(1) & x_{1}(1) & \cdots & x_{m}(1) \\
x_{0}(2) & x_{1}(2) & \cdots & x_{m}(2) \\
\vdots & \vdots & \cdots & \vdots \\
x_{0}(n) & x_{1}(n) & \cdots & x_{m}(n)
\end{array}\right) \text {, }
$$

where $n$ represents the number of indexes. And $X_{i}=$ $\left(x_{i}(1), x_{i}(2), \ldots, x_{i}(n)\right), i=1,2, \ldots, m$.

(2) Apply dimensionless method to the original data sequences; let the dimensionless model be

$$
x_{i}^{\prime}(k)=\frac{x_{i}(k)}{(1 / n) \sum_{k=1}^{n} x_{i}(k)}, \quad i=0,1, \ldots, m ; k=1,2, \ldots, n .
$$

Thus the new data sequences processed by dimensionless model may be rewritten as

$$
\left(X_{0}, X_{1}, \ldots, X_{m}\right)=\left(\begin{array}{cccc}
x_{0}^{\prime}(1) & x_{1}^{\prime}(1) & \cdots & x_{m}^{\prime}(1) \\
x_{0}^{\prime}(2) & x_{1}^{\prime}(2) & \cdots & x_{m}^{\prime}(2) \\
\vdots & \vdots & \cdots & \vdots \\
x_{0}^{\prime}(n) & x_{1}^{\prime}(n) & \cdots & x_{m}^{\prime}(n)
\end{array}\right) .
$$

(3) Define the reference sequence $X_{0}^{\prime}$. The reference sequence consists of the most optimal value or the worst value of every index. That is, $X_{0}^{\prime}=\left(x_{0}^{\prime}(1), x_{0}^{\prime}(2), \ldots, x_{0}^{\prime}(n)\right)$. Accordingly, the rest of the data is as compare sequence.

(4) Compute the distance measure between the corresponding elements of the reference sequence $X_{0}^{\prime}(k)$ and compare sequence $X_{i}^{\prime}(k)$; that is, $\Delta_{0 i k}=\left\|x_{0}^{\prime}(k)-x_{i}^{\prime}(k)\right\|$.

(5) Calculate $\Delta_{\max }, \Delta_{\min }$ using the formula (3); that is,

$$
\begin{aligned}
& \Delta_{\max }=\max _{i} \max _{k}\left\|x_{0}^{\prime}(k)-x_{i}^{\prime}(k)\right\|, \\
& \Delta_{\min }=\min _{i} \min _{k}\left\|x_{0}^{\prime}(k)-x_{i}^{\prime}(k)\right\| .
\end{aligned}
$$

(6) Compute the correlation coefficient between vector $x_{0}^{\prime}(k)$ and vector $x_{i}^{\prime}(k)$ by formulas (4) and (5); that is,

$$
r\left(x_{0}^{\prime}(k), x_{i}^{\prime}(k)\right)=\frac{\Delta_{\min }+\xi \Delta_{\max }}{\Delta_{0 i k}+\xi \Delta_{\max }} .
$$

Notice that $\xi$ is the resolution coefficients and the values of $\xi$ are usually restricted to a certain range $(0,1)$. To keep things simple, put $\xi=0.5$ in this paper.

(7) Compute the correlation degree between reference sequence $X_{0}$ and compare sequence $X_{i}$ by formula (6), and then obtain the evaluation conclusion by comparing the size of correlation degree. 


\section{Model and Algorithm of Fault Diagnosis of Power Systems Based on Gray System Theory}

\subsection{Overall Description of Fault Diagnosis of Power Systems.} Firstly, when some relevant components of power systems malfunction, the corresponding protective relays and circuit breakers will work actively and the fault components will be disconnected with the power supplier. So the power supply interrupted districts will be formed. And then analyzing and eliminating breakdown will be also made in the power supply interrupted districts. Secondly, in the blackout area, the working principle of protective relays and circuit breakers will be analyzed in detail, and the information of the protective relays and circuit breakers, which are in fault state, may be deduced. And based on what is mentioned above, we may establish the state vector of the fault modes and quarantined modes of the components and give the assignment principle of the value for each member of the vector. Finally, the correlation degree between the reference component and compare component will be calculated and sorted. The discriminant criterion is that the component with maximum correlation value is as the fault component. Moreover, the numbers of fault components increase constantly. When the information explanation degree of fault components reaches a specified threshold and the numbers of protective relays and circuit breakers which fail to operate or refused operation do not increase, the number of fault components is determined. According to the order of correlation degree, those components which have same account of maloperation and refused operation are regarded as the fault component. So the ultimate goal of the fault diagnosis is also accomplished.

Obviously, some basic concepts should be explained such as the power supply interrupted districts, fault information explanation degree, and judging rule of maloperation and refused operation. Next, these related concepts and model will be explained step by step.

\subsection{Quick Recognition for the Power Supply Interrupted} Districts. The formation mechanism of the power supply interrupted districts is established on the difference of the topological structures of power systems before and after fault occurrence. When the fault happens, the protection action will be implemented to trip the relevant circuit breakers and the fault components can be isolated from the systems for avoiding the expansion of accident. On the basis of the real time information of the circuit breaker, the topologies of systems before and after fault occurrence are recognized by the real time topology analysis on power systems. And the fault components can automatically form some passive networks according to the difference of the information of the topological structures. So these passive networks are regarded as the power supply interrupted districts. Thus, the recognition of fault components may be limited to the blackout area.

The specific steps [12] are shown as follows.

(1) Based on topology analysis for the normal power systems, the corresponding equivalent power or the generator are remarked as the active nodes.

(2) The topology analysis is made for the faulty system again, and several subsystems are achieved at the same time according to the different information of the topological structures.

(3) The nodes of each subsystem are searched for one by one, and every component connected with each node is active or is not judged. If the component is active, the subsystem is in the normal state, and the search ends; otherwise, if all components in a subsystem are searched for and no active components are found, the subsystem is regarded as the power supply interrupted district.

3.3. Construction for Fault State Vectors and Assignment Principle for Vector Elements. The state vectors are established by means of the protective relays and circuit breakers. If there are $n$ circuit breakers and $m$ protective relays, the form of state vectors can be expressed as

$$
\begin{array}{r}
F(k)=(R, C)=\left(r_{1}, r_{2}, \ldots, r_{m}, c_{1}, c_{2}, \ldots, c_{m}\right), \\
k=1,2, \ldots, n,
\end{array}
$$

where $R$ is the state value of protective relays and $C$ is the state value of circuit breakers. The assignment principle of vector elements is as follows.

(1) If the protective relay run in active mode, then $r_{i}=1$, $i=1,2, \ldots, m$; otherwise $r_{i}=0$.

(2) Analogously, if the circuit breaker is kept in off state, then $c_{i}=1, i=1,2, \ldots, n$; otherwise $c_{i}=0$.

(3) When the state of the element possesses two modes simultaneously, the information of the protective relays conflicts with the information of the circuit breakers. That is to say, the value of state is both 1 and 0 . In that case, the value of $R$ and $C$ is given as 0.5 ; that is, $r_{i}=0.5, i=1,2, \ldots, m ; c_{i}=0.5, i=1,2, \ldots, n$.

3.4. Modeling the Fault Information Explanation Degree. Fault information explanation degree (FIED) is the matching degree of quarantined state vector and fault state vector of multicomponent system. In the other words, it is used for explaining the behavior of protective relays and circuit breakers when the fault of multicomponent systems happens.

Let $F_{A}, F_{B}, \ldots, F_{X}$, whose sizes of dimension are all $1 \times$ $(m+n)$, be the fault state vector, respectively, to single-fault components $A, B, \ldots, X . F_{0}$ is quarantined state vector with $1 \times(m+n)$ dimension.

Therefore, the fault information explanation degree (FIED) of single component can be expressed by the following formula:

FIED $=(($ the number of elements whose values are all greater than 1 among $\left.\left(F_{A}+F_{0}\right)\right)$ 
$\times($ the number of elements

whose values are all equal to 1$\left.)^{-1}\right) \times 100 \%$.

If there are more than one faulty component in power system, FIED can be presented as follows:

FIED $=(($ the number of elements whose values are

all greater than 1

$$
\text { in } \left.\left[\left(F_{A}+F_{0}\right) \vee\left(F_{B}+F_{0}\right) \vee\left(F_{C}+F_{0}\right) \vee \cdots\right]\right)
$$

$\times$ (the number of elements

$$
\text { whose values are all equal to } \left.1)^{-1}\right) \times 100 \% \text {, }
$$

where the symbol " $V$ " denotes that the greater value is selected for the values of corresponding elements.

To locate out the fault components in systems, we need to compare the size of FIED. Once FIED satisfies FIED $=100 \%$, the fault components may be determined by formulas (13) and (14).

3.5. Judging Method of Malfunction and Rejection for Protective Relays and Circuit Breakers. According to the assumption and analysis above, the judging rule is designed as follows.

(1) If the value of element of the vector $\left(F_{A}-F_{0}\right)$ is negative, then the corresponding protection of protective relays or action of circuit breakers is regarded as malfunction for single-component fault. Otherwise, the protection of protective relays or trip of circuit breakers is regarded as rejecting action.

(2) If there is more than one fault component in the system, the judging rule is as follows. The protection of protective relays or action of circuit breakers is regarded as malfunction while the value of the vector $\left(\left(F_{A} \vee F_{B} \vee F_{C} \vee \cdots\right)\right.$ $F_{0}$ ) is negative; otherwise the action is regarded as rejecting action.

Notice that when failures happen, the main protection of PRs is first implemented to trip the circuit breakers. If the main protective relays do not work, then the backup protective relays begin to work to trip the circuit breakers. Therefore, the situation of the backup PRs deduced by (1) and (2) was the rejecting action; it may be that the action of PRs has already tripped the action of CBs. So we concern only the main protective relays and the circuit breakers and then give priority to main PRs when the malfunction and rejecting action are considered in this paper.

3.6. Fault Diagnosis Model of Single Component. The problem of recognition for single-fault component can be solved by seeking for the fault assumptions, which can best explain the alarming information and can be expressed by the following maximization problem:

$$
\begin{aligned}
R_{i}=\frac{1}{n} \sum_{k=1}^{n}( & \left(\min _{i} \min _{k}\left|F_{0}(k)-F_{i}(k)\right|\right. \\
& \left.+\xi \max _{i} \max _{k}\left|F_{0}(k)-F_{i}(k)\right|\right) \\
& \times\left(\left|F_{0}(k)-F_{i}(k)\right|\right. \\
& \left.\left.+\xi \max _{i} \max _{k}\left|F_{0}(k)-F_{i}(k)\right|\right)^{-1}\right),
\end{aligned}
$$

where $i$ stands for the total number of the single-fault, and its value is determined by adding the number of components and the number of lines; $n$ denotes the number of vector elements, and its value is the number of protective relays and circuit breakers; $\xi$ is on behalf of the resolution coefficient; $F_{0}(k)$ indicates the quarantined faulty state vector; $F_{i}(k)$ means the fault state vector of single-line or single component and also is called the single-fault state vector; $R_{i}$ represents the similarity degree between the quarantined fault state vector and single-fault state vector and also is called correlation degree.

Notice that if the state vector of single-fault component $A, B, \ldots, X$ is $F_{A}, F_{B}, \ldots, F_{X}$, respectively, then the dimension of these state vectors is $1 *(m+n)$ and the dimension of the quarantined fault state vector $F_{0}$ is also $1 *(m+$ $n)$. Meanwhile, we may calculate the correlation degree and sort the calculated results. Based on above discussion, the recognition rule of fault component is given as follows.

Rule 1. If the correlation degree between the reference state vector $F_{0}$ and the compare state vector $F_{i}(i=A, B, \ldots, X)$ is the largest, the corresponding part is fault component or fault line.

Rule 2. Let the threshold of fault diagnosis be the mean of correlation degree. If the correlation degree between the reference state vector $F_{0}$ and new compare state vector $F_{N}$ is more than the threshold, the part is regarded as the fault component or fault line.

Therefore, the possibility that fault happens may be determined for every single component according to Rules 1 and 2 .

3.7. Diagnostic Procedure for Fault Components. In the actual project, there is more than one fault component when faults occur. But the diagnostic procedure may be designed on the basis of the fault diagnosis model of single component. So the specific steps of fault diagnosis are shown as follows.

3.7.1. Data Preprocessing. The data, which contains the information of protective relays and circuit breakers and the topology of the power system, is written in the system. 


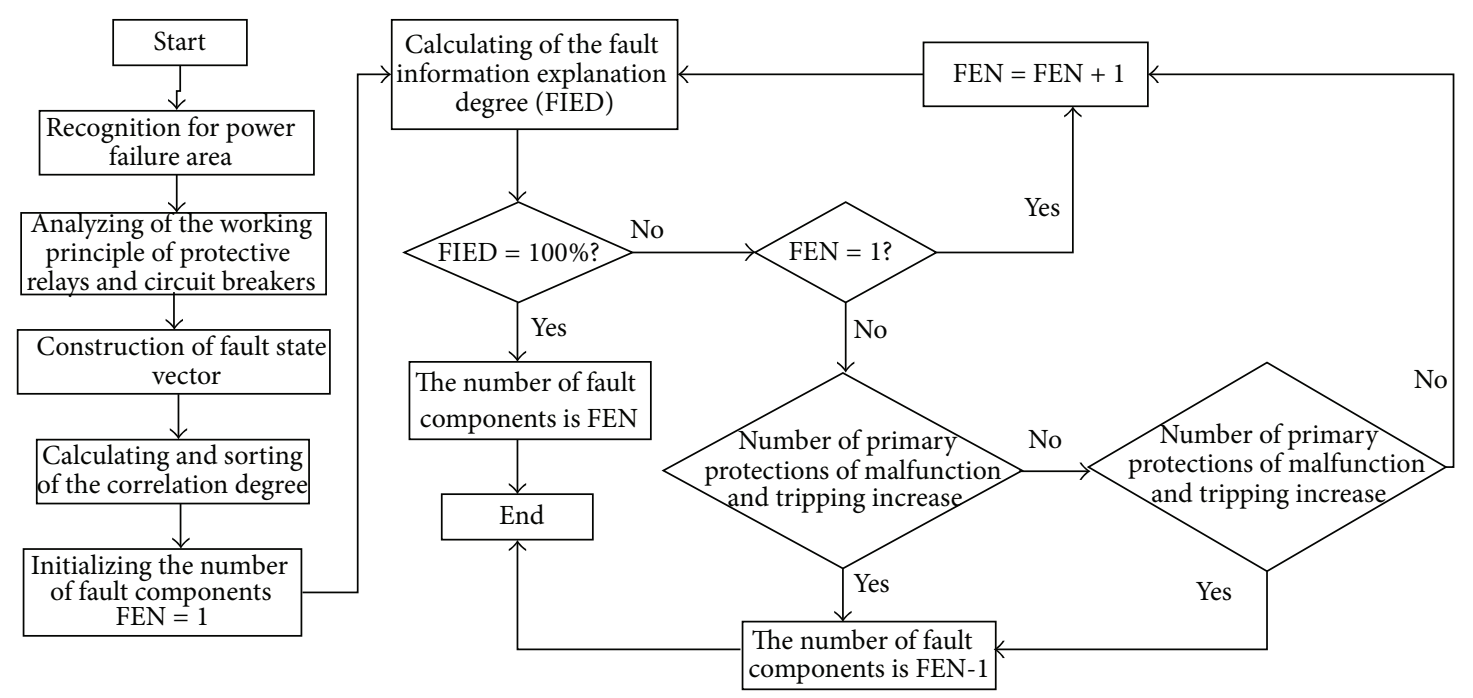

FIgURE 1: The flowchart for fault diagnosis.

3.7.2. Recognition for the Power Supply Interrupted Districts. The blackout area of power systems is recognized, and the tripping principle of protective relays and circuit breaker in blackout area is listed.

3.7.3. Recognition of State Information. Under single-fault state, the state information of protective relays and circuit breaker is obtained in accordance with the working principle of protective relays and circuit breakers.

3.7.4. Construction for Fault State Vectors. The state vector of fault mode for each component is given by the assignment principle of vector elements, and then the quarantined fault state vector is loaded.

3.7.5. Calculating and Sorting the Correlation Degree. The correlation coefficients are calculated, respectively, and then these results are sorted. If the correlation degree between quarantined state vector and reference state vector is the highest, the probability that component malfunctions is also the largest.

3.7.6. Computing Fault Information Explanation Degree. FIED is calculated by formulas (13) and (14) and is sorted. If FIED of some fault components satisfies FIED $=100 \%$, go to next step.

3.7.7. Fault Diagnosis Analysis. According to Rules 1 and 2, the fault component can be recognized and diagnosed. And then judge the malfunction and rejection for protective relays and circuit breakers.

The specific flowchart for fault diagnosis is shown as in Figure 1.

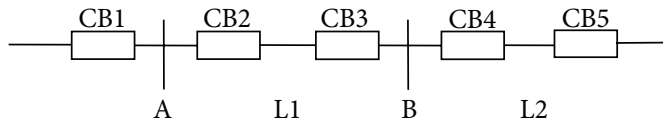

FIGURE 2: Framework of simple circuit structure.

\section{Experiment and Its Results Analysis}

Firstly, regarding the simple circuit structure shown in Figure 2 as the power supply interrupted districts, the following sections will explain and demonstrate in detail how to use the working principle of protection action to identify the state vectors of fault components.

Obviously, the simple system shown in Figure 2 consists of 4 elements (i.e., A, B, L1, and L2) and 5 circuit breakers (i.e., $\mathrm{CB} 1, \mathrm{CB} 2, \mathrm{CB} 3, \mathrm{CB} 4$, and $\mathrm{CB} 5)$. So there are 14 protection actions, respectively, that is, $\mathrm{A}_{m}, \mathrm{~B}_{m}, \mathrm{~L} 1 \mathrm{~A}_{m}, \mathrm{~L}_{m}, \mathrm{~L}_{2} \mathrm{~B}_{m}$, $\mathrm{L}_{2} \mathrm{C}_{m}, \mathrm{~L} 1 \mathrm{~A}_{p}, \mathrm{~L} 1 B_{p}, \mathrm{~L} 2 \mathrm{~B}_{p}, \mathrm{~L}_{2} \mathrm{C}_{p}, \mathrm{~L} 1 \mathrm{~A}_{s}, \mathrm{~L} 1 B_{s}, \mathrm{~L} 2 \mathrm{~B}_{s}$, and L2C . To make things simple, these protection actions are represented symbolically by $r_{1}, r_{2}, \ldots, r_{14}$. Note that, in this example, A and $\mathrm{B}$ are Bus, L represents Line, the subscript $m$ denotes the primary protection, $s$ stands for the first backup protection, and $p$ is on behalf of the second backup protection. Through analysis of the circuit structure, the working principle of the primary protection and the backup protection is listed in Table 1 .

According to the working principle of primary protection and backup protection shown in Table 1, the state information of protective relays and circuit breakers is deduced as shown in Table 2.

Let $c_{i}(i=1,2, \ldots, 5)$ denote the action of five circuit breakers. Thus, by combining with the state information shown in Table 2, the fault state vector of every component may be determined using the assignment principle introduced in Section 3.3. Therefore, the fault state vector of every element is shown in Table 3. 
TABLE 1: Working principle of protective relays and circuit breakers.

\begin{tabular}{|c|c|c|}
\hline Number & Name & $\begin{array}{l}\text { Corresponding action of protective } \\
\text { relays and circuit breakers }\end{array}$ \\
\hline$r_{1}$ & $\mathrm{~A}_{m}$ & $\begin{array}{l}\text { Fault: } A \text {; action: } A_{m} \text {; tripping: } C B 1 \text { and } \\
\text { CB2 }\end{array}$ \\
\hline$r_{2}$ & $\mathrm{~B}_{m}$ & $\begin{array}{l}\text { Fault: } \mathrm{B} \text {; action: } \mathrm{B}_{m} \text {; tripping: } \mathrm{CB} 3 \text { and } \\
\text { CB4 }\end{array}$ \\
\hline$r_{3}$ & $\mathrm{~L} 1 \mathrm{~A}_{m}$ & Fault: L1; action: $\mathrm{L} \mathrm{A}_{m}$; tripping: CB2 \\
\hline$r_{4}$ & $\mathrm{~L} 1 \mathrm{~B}_{m}$ & Fault: L1; action: $\mathrm{L} 1 \mathrm{~B}_{m}$; tripping: $\mathrm{CB} 3$ \\
\hline$r_{5}$ & $\mathrm{~L}_{2} \mathrm{~B}_{m}$ & Fault: L2; action: ${\mathrm{L} 2 \mathrm{~B}_{m}}$; tripping: $\mathrm{CB} 4$ \\
\hline$r_{6}$ & $\mathrm{~L}_{2} \mathrm{C}_{m}$ & Fault: $\mathrm{L} 2$; action: $\mathrm{L}_{2} \mathrm{C}_{m}$; tripping: $\mathrm{CB} 5$ \\
\hline$r_{7}$ & $\mathrm{~L} 1 \mathrm{~A}_{p}$ & $\begin{array}{l}\text { Fault: } \mathrm{L} 1 \text {; unaction: } \mathrm{L} \mathrm{A}_{m} ; \text { action: } \\
\mathrm{L} 1 \mathrm{~A}_{p} \text {; tripping: CB2 }\end{array}$ \\
\hline$r_{8}$ & $\mathrm{~L} 1 \mathrm{~B}_{p}$ & $\begin{array}{l}\text { Fault: } \mathrm{L} 1 \text {; unaction: } \mathrm{L}^{1} B_{m} \text {; action: } \mathrm{L}_{1} \text {; } \\
\text { tripping: CB3 }\end{array}$ \\
\hline$r_{9}$ & $\mathrm{~L}_{2} \mathrm{~B}_{p}$ & 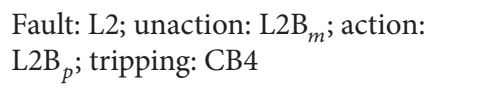 \\
\hline$r_{10}$ & $\mathrm{~L}^{2} \mathrm{C}_{p}$ & $\begin{array}{l}\text { Fault: } \mathrm{L} 2 \text {; unaction: } \mathrm{L}_{2} \mathrm{C}_{m} \text {; action: } \\
\mathrm{L}_{2} \mathrm{C}_{p} \text {; tripping: } \mathrm{CB} 5\end{array}$ \\
\hline$r_{11}$ & $\mathrm{~L} A_{s}$ & $\begin{array}{l}\text { Fault: } \mathrm{B} \text {; untripping: } \mathrm{CB} 3 \text {; action: } \mathrm{L} \mathrm{A}_{s} \text {; } \\
\text { tripping: } \mathrm{CB} 2 \text {; } \\
\text { or fault: } \mathrm{L} 2 \text {; untripping: } \mathrm{CB} 3 \text { and } \mathrm{CB} 4 \text {; } \\
\text { action: } \mathrm{L}_{\mathrm{s}} \text {; tripping: } \mathrm{CB} 2\end{array}$ \\
\hline$r_{12}$ & $\mathrm{~L} 1 B_{s}$ & $\begin{array}{l}\text { Fault: A; untripping: } \mathrm{CB} 2 \text {; action: } \mathrm{L} \mathrm{B}_{s} \text {; } \\
\text { tripping: } \mathrm{CB} 3\end{array}$ \\
\hline$r_{13}$ & $\mathrm{~L}_{2} \mathrm{~B}_{s}$ & $\begin{array}{l}\text { Fault: C; untripping: } \mathrm{CB} 5 \text {; action: } \mathrm{L}^{2} \mathrm{~B}_{s} \text {; } \\
\text { tripping: } \mathrm{CB} 4\end{array}$ \\
\hline$r_{14}$ & $\mathrm{~L}_{2} \mathrm{C}_{s}$ & $\begin{array}{l}\text { Fault: } \mathrm{B} \text {; untripping: } \mathrm{CB} 4 \text {; action: } \\
\text { L2C } \mathrm{C}_{s} \text {; tripping: } \mathrm{CB} 5 \text {; } \\
\text { or fault: } \mathrm{L} 1 \text {; untripping: } \mathrm{CB} 3 \text { and } \mathrm{CB} 4 \text {; } \\
\text { action: } \mathrm{L}_{2} \text {; tripping: } \mathrm{CB} 5\end{array}$ \\
\hline
\end{tabular}

TABLE 2: State information of protective relays and circuit breakers.

\begin{tabular}{|c|c|}
\hline Fault nodes & $\begin{array}{l}\text { The state information for protective relays and } \\
\text { circuit break }\end{array}$ \\
\hline A & $\begin{array}{l}r_{1}=1, \mathrm{CB} 1=1 \text { and } \mathrm{CB} 2=1 \text { or } r_{12}=1, \mathrm{CB} 2=0 \\
\text { and } \mathrm{CB} 3=1\end{array}$ \\
\hline B & $\begin{array}{l}r_{2}=1, \mathrm{CB} 3=1 \text { and } \mathrm{CB} 4=1 \text { or } r_{11}=1, \mathrm{CB} 3=0 \\
\text { and } \mathrm{CB} 2=1 \text { or } r_{14}=1, \mathrm{CB} 4=0 \text { and } \mathrm{CB} 5=1\end{array}$ \\
\hline $\mathrm{L} 1$ & $\begin{array}{l}r_{3}=1 \text { and } \mathrm{CB} 2=1 \text { or } r_{4}=1 \text { and } \mathrm{CB} 3=1 \text { or } r_{7}= \\
1, r_{3}=0 \text {, and } \mathrm{CB} 2=1 \text { or } r_{8}=1, r_{4}=0 \text {, and } \mathrm{CB} 3 \\
=1 \text { or } r_{14}=1, \mathrm{CB} 3=0, \mathrm{CB} 4=0 \text {, and } \mathrm{CB} 5=1\end{array}$ \\
\hline L2 & $\begin{array}{l}r_{5}=1 \text { and } \mathrm{CB} 4=1 \text { or } r_{6}=1 \text { and } \mathrm{CB} 5=1 \text { or } r_{9}= \\
1, r_{5}=0 \text {, and } \mathrm{CB} 4=1 \text { or } r_{10}=1, r_{6}=0 \text {, and } \mathrm{CB} 5 \\
=1 \text { or } r_{11}=1, \mathrm{CB} 3=0, \mathrm{CB} 4=0, \text { and } \mathrm{CB} 2=1\end{array}$ \\
\hline
\end{tabular}

If a quarantined fault state vector obtained by alarming information is $\left(r_{1}, r_{5}, r_{6}, c_{1}, c_{2}, c_{4}, c_{5}\right)$ and it needs to determine which node is in fault, we need to compare the size of correlation coefficient between quarantined fault state and reference state vector. According the data in Table 3, the correlation degree may be computed by formula (15); that is,

$$
\begin{array}{ll}
r_{\mathrm{A}}=0.8333, & r_{\mathrm{B}}=0.8247 \\
r_{\mathrm{L} 1}=0.7807, & r_{\mathrm{L} 2}=0.8509
\end{array}
$$

The sorting result is

$$
r_{\mathrm{L} 2}>r_{\mathrm{A}}>r_{\mathrm{B}}>r_{\mathrm{L} 1} \text {. }
$$

So we can infer that the probability that the Line L2 malfunctions is maximum, and then the number of fault elements (FEN) is 1; that is, there is only one fault component L2 in systems. In this case, we may get

$$
\text { FIED }=(5 \div 7) \times 100 \%=71.4 \% \text {. }
$$

Obviously, the fault component cannot be completely determined. Through analysis of the information data, when there are two fault components L2 and A, FIED is

$$
\text { FIED }=(7 \div 7) \times 100 \%=100 \% \text {. }
$$

Therefore, the quarantined state vector indicates that two components L2 and A are failure.

Meanwhile,

$$
\begin{gathered}
F_{\mathrm{L} 2} \vee F_{\mathrm{A}}=\left(r_{1}, \frac{r_{5}}{2}, \frac{r_{6}}{2}, r_{9}, r_{10}, r_{11}, r_{12}, c_{1}, c_{2}, c_{3}, \frac{c_{4}}{2}, c_{5}\right), \\
F_{\mathrm{L} 2} \vee F_{\mathrm{A}}-F_{0}=\left(-\frac{r_{5}}{2},-\frac{r_{6}}{2}, r_{9}, r_{10}, r_{11}, r_{12}, c_{3},-c_{4}\right) .
\end{gathered}
$$

By the judging rule of malfunction and rejection, the primary protection which corresponds to $r_{5}$ and $r_{6}$ and the action $c_{4}$ which corresponds to the circuit breaker CB4 is regarded as malfunction. Note that the alarming information is $\left(r_{1}, r_{5}, r_{6}, c_{1}, c_{2}, c_{4}, c_{5}\right)$, and the action $c_{3}$ shown in formula (21) is a rejection. In other words, the information which corresponds to the action of the circuit breaker CB3 has lost. Namely, the more accurate diagnosis results can be obtained by the algorithm even if some information has lost in systems.

The above computing process has primarily illustrated the calculated steps of fault diagnosis algorithm based on Gray systems theory. And the results indicate that the algorithm is effective and reasonable. To further explain and verify the rationality and effectiveness of the method mentioned in this paper, we take the classic system structure of local power relay protection shown by [9], which contains 28 components, 84 protective relays, and 40 circuit breakers, to analyze the diagnosis procedure. The structure of the local power systems is shown in Figure 3.

Where $\mathrm{A}$ and $\mathrm{B}$ denote Bus, $\mathrm{L}$ is Line, $\mathrm{T}$ represents Transformer, and CB is circuit breaker.

As can be seen in Figure 3, 28 components are A1, A2, A3, A4, T1, T2, T3, T4, T5, T6, T7, T8, B1, B2, B3, B4, B5, B6, B7, B8, L1, L2, L3, L4, L5, L6, L7, and L8; 84 protections are consisting of 36 primary protections and 48 backup protections, where 36 primary protections are, respectively, $\mathrm{A} 1_{m}, \mathrm{~B} 1_{m}, \mathrm{~B} 2_{m}, \mathrm{~B} 3_{m}, \mathrm{~B} 4_{m}, \mathrm{~B} 5_{m}, \mathrm{~B} 6_{m}, \mathrm{~B} 7_{m}, \mathrm{~B} 8_{m}, \mathrm{~L}_{S_{m}},{\mathrm{~L} 1 R_{m}}_{m}$, $\mathrm{L}_{2} \mathrm{~S}_{m}, \mathrm{~L}_{2} \mathrm{R}_{m}, \mathrm{~L}_{3} \mathrm{~S}_{m}, \mathrm{~L}_{3}, \mathrm{~L}_{m} 4 \mathrm{~S}_{m}, \mathrm{~L}_{4}, \mathrm{~L}_{m} 5 \mathrm{~S}_{m}, \mathrm{~L}_{m}, \mathrm{~L}_{m}$, ${\mathrm{L} 6 \mathrm{R}_{m}}_{m}, \mathrm{~L}_{m}, \mathrm{~L}_{m}, \mathrm{~L}_{m}$, and $\mathrm{L}_{m} \mathrm{R}_{m} ; 48$ backup protections are as follows: $\mathrm{T}_{p}, \mathrm{~T} 2_{p}, \mathrm{~T} 3_{p}, \mathrm{~T} 4_{p}, \mathrm{~T} 5_{p}, \mathrm{~T} 6_{p}, \mathrm{~T} 7_{p}, \mathrm{~T} 8_{p}, \mathrm{~T} 1_{s}, \mathrm{~T} 2_{s}$,

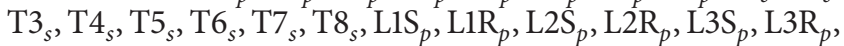
$\mathrm{L}_{4}, \mathrm{~L}_{p}, \mathrm{~L}_{\mathrm{S}}, \mathrm{L}_{\mathrm{R}}, \mathrm{L}_{\mathrm{s}}, \mathrm{L}_{\mathrm{p}}, \mathrm{L}_{\mathrm{s}}, \mathrm{L}_{\mathrm{p}}, \mathrm{L}_{\mathrm{s}}, \mathrm{L}_{\mathrm{s}} \mathrm{R}_{p}$, $\mathrm{L}_{s}, \mathrm{~L} 1 R_{s}, \mathrm{~L}_{2}, \mathrm{~L}_{s}, \mathrm{~L}_{s}, \mathrm{~L}_{s}, \mathrm{~L}_{s}, \mathrm{~L}_{4}, \mathrm{~L}_{s} \mathrm{~S}_{s}, \mathrm{~L} \mathrm{R}_{s}, \mathrm{~L} 6 \mathrm{~S}_{s}$, $\mathrm{L} 6 \mathrm{R}_{s}, \mathrm{~L}_{s}, \mathrm{~L}_{s}, \mathrm{~L}_{s}$, and $\mathrm{L} 8 \mathrm{R}_{s}$. 
TABLE 3: State vectors of fault component.

\begin{tabular}{lcc}
\hline Fault node & The state vectors $\left(r_{1}, r_{2}, \ldots, r_{14}, c_{1}, c_{2}, \ldots, c_{5}\right)$ & Simple forms \\
\hline A & $(1,0,0,0,0,0,0,0,0,0,0,1,0,0,1,0.5,1,0,0)$ & $\left(r_{1}, r_{12}, c_{1}, c_{2} / 2, c_{3}\right)$ \\
B & $(0,1,0,0,0,0,0,0,0,0,1,0,0,1,0,1,0.5,0.5,1)$ & $\left(r_{2}, r_{11}, r_{14}, c_{2}, c_{3} / 2, c_{4} / 2, c_{5}\right)$ \\
L1 & $(0,0,0.5,0.5,0,0,1,1,0,0,0,0,0,1,0,1,0.5,0,1)$ & $\left(r_{3} / 2, r_{4} / 2, r_{7}, r_{8}, r_{14}, c_{2}, c_{3} / 2, c_{5}\right)$ \\
L2 & $(0,0,0,0,0.5,0.5,0,0,1,1,1,0,0,0,0,1,0,0.5,1)$ & $\left(r_{5} / 2, r_{6} / 2, r_{9}, r_{10}, r_{11}, c_{2}, c_{4} / 2, c_{5}\right)$ \\
\hline
\end{tabular}

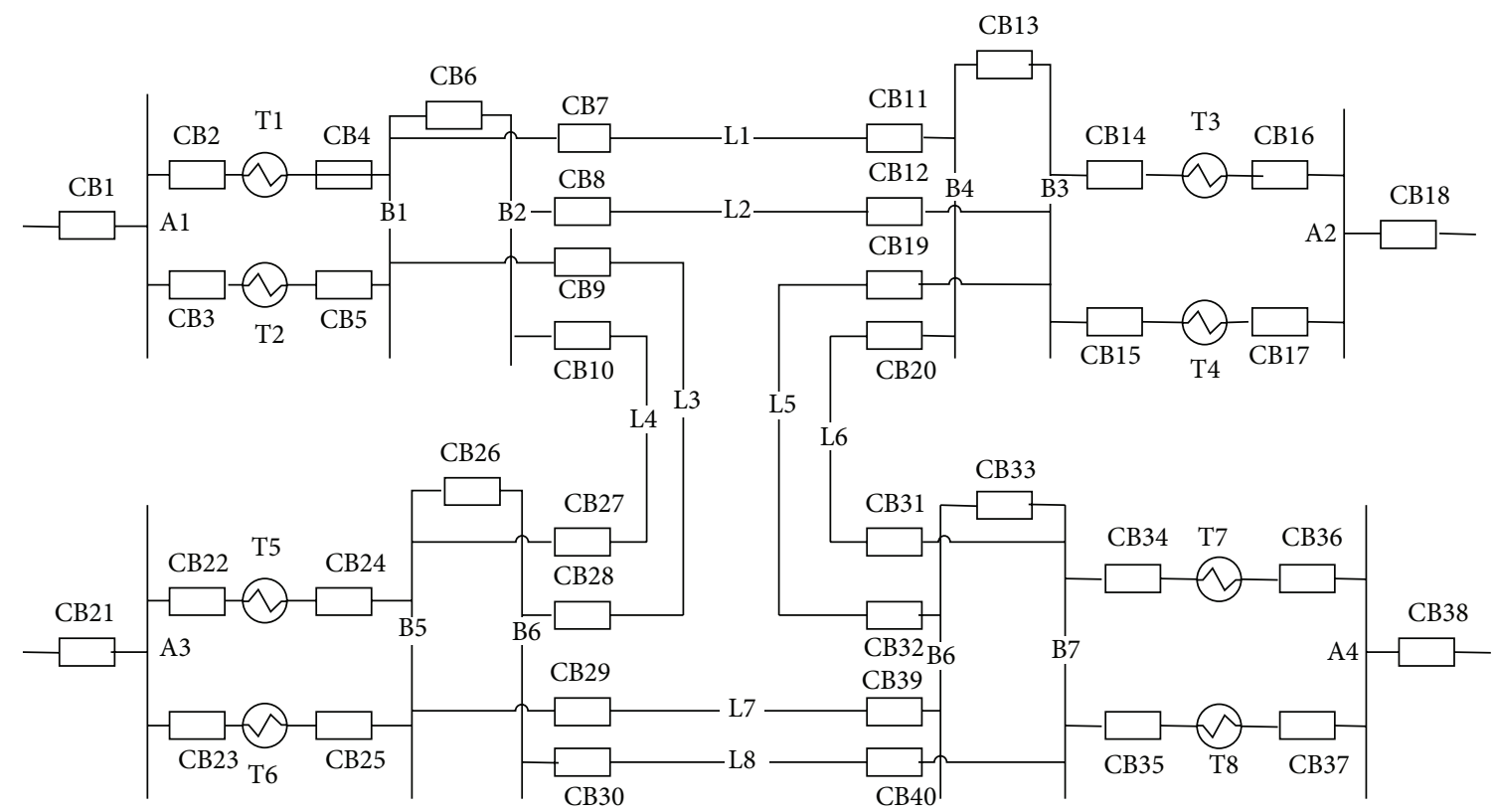

FIGURE 3: Classic system structure of the local power relay protection.

And the meaning of these symbols is, respectively, as follows: $\mathrm{S}$ is Sending End of Line and $\mathrm{R}$ is Receiving End, $m$ is primary protection, $p$ represents first backup protection, and $s$ is second backup protection. The working principle of these protections may be seen in the Resources [11, 13] section.

By comparing the method proposed in this paper with the methods in $[13,14]$, we are testing out 4 most complicated circumstances in case of incomplete information and complete information to verify the effectiveness of the method. The diagnosis results are listed as in Table 4.

As is shown in Table 4, in case of complete information, the diagnosis result for test sequence 1 and sequence 2 is identical to the results in $[11,12]$; in case of incomplete information, the diagnosis result for test sequence 3 and test sequence 4 is identical to the results in [11], but it is not identical to the result in [12]. This is because there are some lost information in test sequence 3 and test sequence 4 .

Therefore, to further test this algorithm proposed in this paper, we apply the presented algorithm in this paper and the Bayesian algorithm in [12] to diagnose the power supply in intelligent traffic systems (ITS). The detecting information of the power supply in ITS contains the PT break-phase, CT signal, volts d.c. and current, synchronous signal, temperature of sensors, and the Airborne capacity. In real application, the fitting curve between using the two methods is as in Figure 4.
Figure 4(a) showed the whole effect of diagnosis procedure. Correspondingly, Figures 4(b) and 4(c) described the part effect of diagnosis algorithm. This indicates that the error between using the two methods is very small. This indicates that the algorithm presented in this paper is reasonable.

However, the running stability of real system needs to be ensured for any algorithm, whether or not the algorithm is effective and reasonable. That is to say, the stability of the diagnosis procedure should to be analyzed. For verifying the rationality of the designed algorithm, the anticipant precision threshold is set as 0.01 and every running test time is set as 1000 epochs. The total running performance is shown as in Figure 5.

The running effect of diagnosis system indicated that the abnormal phenomenon of the security running took place at 20th second, and then the parameter of systems needs to be adjusted to ensure the systems normal running. Figure 5 displays that the abnormal phenomena of the designed diagnosis systems seem to change small in warning, and yet the running performance is very stable during the whole running process. To find out why the danger happens, we take the running performance chart from 0 th second to 40 th second as in Figure 6.

Figure 6 displays that the interior change of diagnosis system was quite rapid. Simultaneously, there exists a glacis from the initial warning to normal running. As a result, the 
TABLE 4: Part of the test results.

\begin{tabular}{|c|c|c|c|c|c|c|}
\hline $\begin{array}{l}\text { Test } \\
\text { sequences }\end{array}$ & Relay action information & $\begin{array}{l}\text { Missing } \\
\text { information }\end{array}$ & $\begin{array}{l}\text { Diagnosis } \\
\text { result }\end{array}$ & $\begin{array}{l}\text { Judgment for } \\
\text { malfunction and } \\
\text { rejection }\end{array}$ & $\begin{array}{l}\text { Diagnosis result } \\
\text { in [11] }\end{array}$ & $\begin{array}{l}\text { Diagnosis result } \\
\text { in }[12]\end{array}$ \\
\hline 1 & $\begin{array}{l}\text { Behavior: T5s, T6s; } \\
\text { tripping: } \mathrm{C}_{21}, \mathrm{C}_{22}, \mathrm{C}_{23}, \mathrm{C}_{24} \text {, } \\
\text { and } \mathrm{C}_{25}\end{array}$ & unexisting & $\mathrm{A} 3$ & $\begin{array}{l}\text { Malfunction: } \mathrm{A}_{m} ; \\
\text { rejection (tripping): } \\
\mathrm{C}_{21}, \mathrm{C}_{24} \text {, and } \mathrm{C}_{25}\end{array}$ & $\mathrm{~A} 3$ & $\mathrm{~A} 3$ \\
\hline 2 & $\begin{array}{c}\text { Behavior: B1m, L2Rs, } \\
\text { L4Rs, } \mathrm{C}_{4} \text {; tripping: } \mathrm{C}_{5}, \mathrm{C}_{7} \text {, } \\
\mathrm{C}_{9}, \mathrm{C}_{12} \text {, and } \mathrm{C}_{27}\end{array}$ & unexisting & B1 & Rejection (tripping): $\mathrm{C}_{6}$ & B1 & B1 \\
\hline 3 & $\begin{array}{l}\text { Behavior: } \mathrm{B} 1 \mathrm{~m}, \mathrm{~L} 4 \mathrm{Rs} ; \\
\text { tripping: } \mathrm{C}_{4}, \mathrm{C}_{7}, \mathrm{C}_{9}, \mathrm{C}_{12} \text {, } \\
\text { and } \mathrm{C}_{27}\end{array}$ & L2Rs, $\mathrm{C}_{5}$ & $\mathrm{~B} 1$ & $\begin{array}{l}\text { Rejection (tripping): } \mathrm{C}_{5} \\
\text { and } \mathrm{C}_{6}\end{array}$ & $\mathrm{~B} 1$ & \\
\hline 4 & $\begin{array}{c}\text { Behavior: } \mathrm{B}_{m}, \mathrm{~T}_{m}, \mathrm{~T}_{m} \text {, } \\
\mathrm{L}_{1} \mathrm{~s}_{m}, \mathrm{~L} 2 \mathrm{RP} \text {; tripping: } \mathrm{C}_{2} \text {, } \\
\mathrm{C}_{3}, \mathrm{C}_{4}, \mathrm{C}_{5}, \mathrm{C}_{7}, \mathrm{C}_{9}, \mathrm{C}_{11} \text {, and } \\
\mathrm{C}_{28}\end{array}$ & $\mathrm{~T} 7 \mathrm{~s}, \mathrm{C}_{6}$ & L1, B1, T1, T2 & $\begin{array}{l}\text { Rejection (tripping): } \\
\text { L1R }_{m}, \mathrm{C}_{6} \text {; malfunction: } \\
\mathrm{C}_{28}\end{array}$ & L1, B1, T1, T2 & \\
\hline
\end{tabular}

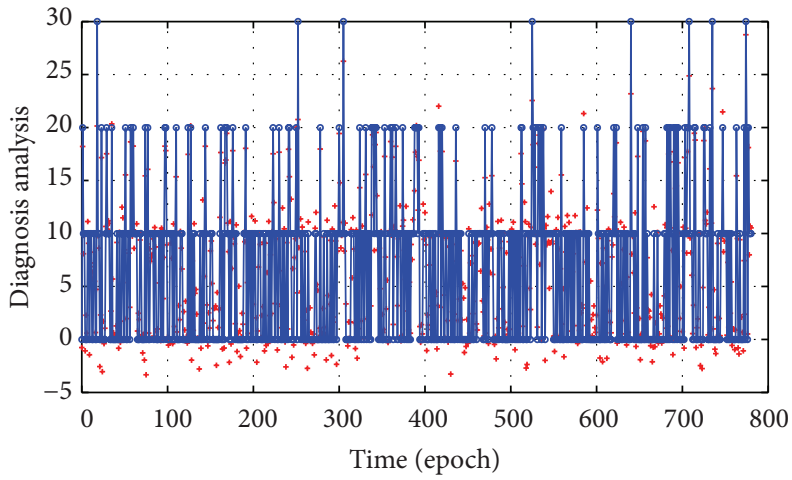

(a)

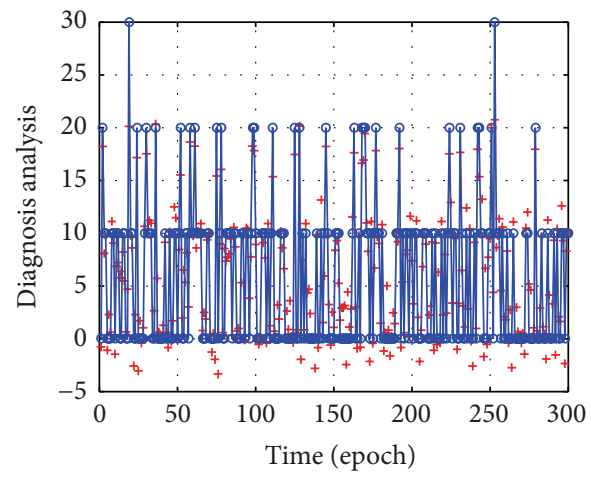

(b)

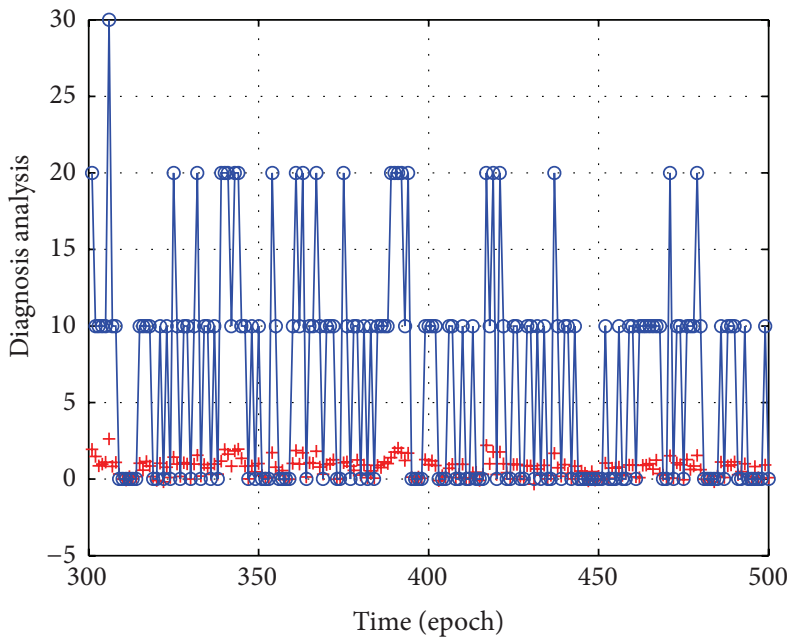

(c)

Figure 4: (a) The fitting curve of test sequence (0-780) using the two methods; (b) The fitting curve of test sequence (0-301) using the two methods; (c) The fitting curve of test sequence (301-500) using the two methods (Note: + indicates the test sequence using Bayesian algorithm in [12]; $O$ indicates the test sequence using Gray theory algorithm). 


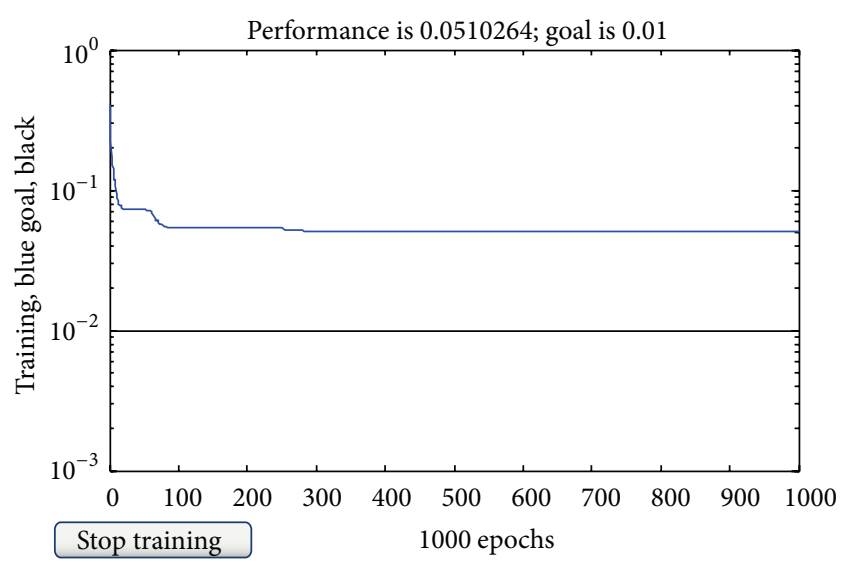

FIGURE 5: The total running performance chart of fault diagnosis for the power supply in ITS.

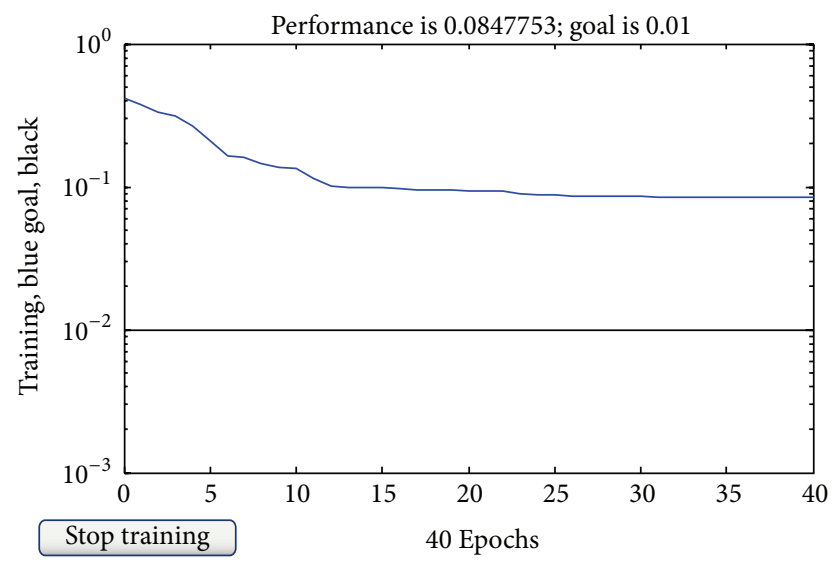

FIGURE 6: The part running performance chart of fault diagnosis for the power supply in ITS.

running effect is in accord with the practical situation. This is because certain period of time is used to adjust parameter of the power supply for ensuring the final stable running of the algorithm.

\section{Conclusion}

Based on the theory of Gray system, a fault diagnosis method in power systems is proposed with respect to the diagnosis problem of incomplete information for protective relays devices in power system, and the analysis of overall architecture and the diagnosis process are conducted. Some simple experiments show that the method presented in this paper is effective and can also carry out the same fault diagnosis task that another traditional diagnosis method completed. Through comparing these diagnosis results, we know that the method may diagnose the fault in case of incomplete and complete information. In addition, through the practical engineering application in ITS, the stability of diagnosis procedure was also analyzed. The simulation result demonstrated that the running stability of the diagnosis procedure is practical and consistent with the operation requirements.

However, owing to the fact that information data comes from different parts of power supply systems in ITS, the running situation of diagnosis systems was influenced. Thereby, the investigation about how to logically distribute the information of power supply device in ITS remains an interesting area for further research. Meanwhile, the method and algorithm presented in this paper can only be used to diagnose and determine which component malfunctions after the abnormal phenomenon of power systems has occurred. But in practical application of power supply devices in ITS, the users always hope that the diagnosis systems can forecast the faults before the fault states of components will happen. So, how to fuse the incomplete and complete information of protective relays and circuit breakers to forecast the faults by GM model, which provides the maintaining decision for the components and lines, is also very important problem in power systems.

\section{Conflict of Interests}

The authors declare that there is no conflict of interests regarding the publication of this paper.

\section{Acknowledgments}

This work is supported by the National Nature Science Foundation (nos. 61004118, 61304104) and Program for Excellent Talents of Chongqing Higher School (no. 2014-18).

\section{References}

[1] W. Fu-Shuan, H. Zhen-Xiang, T. Lei et al., "An analytic model and genetic algorithm based methods for fault diagnosis in power systems, part 1: the model and method," Proceedings of the CSU-EPSA, vol. 10, no. 3, pp. 1-7, 1998.

[2] G. Cardoso Jr., J. G. Rolim, and H. H. Zurn, "Identifying the primary fault section after contingencies in bulk power systems," IEEE Transactions on Power Delivery, vol. 23, no. 3, pp. 1335-1342, 2008.

[3] M. Wang and F. Long, "Fault diagnosis of rectifying circuit using ANN," Journal of Wuhan University of Technology (Transportation Science and Engineering), vol. 37, no. 3, pp. 578-580, 2013.

[4] W. Guo, F. Wen, G. Ledwich, Z. Liao, X. He, and J. Liang, "An analytic model for fault diagnosis in power systems considering malfunctions of protective relays and circuit breakers," IEEE Transactions on Power Delivery, vol. 25, no. 3, pp. 1393-1401, 2010.

[5] Q. Li, Z.-B. Li, and Q. Zhang, "Research of power transformer fault diagnosis system based on rough sets and Bayesian Networks," Advanced Materials Research, vol. 320, pp. 524-529, 2011.

[6] Z. Xin, Power System Fault Diagnosis Based on Rough Set Theory and Bayesian Network, Shandong University, Shandong, China, 2010.

[7] S.-H. Liu and X. Li, "Power system fault diagnosis by use of prediction petri net models," Proceedings of the CSU-EPSA, vol. 25, no. 4, pp. 162-166, 2013. 
[8] Z. J. Zhou, C. H. Hu, J. B. Yang, D. L. Xu, and D. H. Zhou, "Online updating belief-rule-base using the RIMER approach," IEEE Transactions on Systems, Man, and Cybernetics Part A. Systems and Humans, vol. 41, no. 6, pp. 1225-1243, 2011.

[9] B.-C. Zhang, X.-X. Han, Z.-J. Zhou, L. Zhang, X.-J. Yin, and Y.W. Chen, "Construction of a new BRB based model for time series forecasting," Applied Soft Computing Journal, vol. 13, no. 12, pp. 4548-4556, 2013.

[10] H. Dong, Z. Wang, and H. Gao, "Distributed $H_{\infty}$ filtering for a class of markovian jump nonlinear time-delay systems over lossy sensor networks," IEEE Transactions on Industrial Electronics, vol. 60, no. 10, pp. 4665-4672, 2013.

[11] Z. Wang, H. Dong, B. Shen, and H. Gao, "Finite-horizon $H_{\infty}$ filtering with missing measurements and quantization effects," IEEE Transactions on Automatic Control, vol. 58, no. 7, pp. 17071718, 2013.

[12] F. Wen, Y. Qian, and Z. Han, "A Tabu search b Based approach to fault section estimation and state identification of unobserved protective relays in power systems using information from protective relays and circuit breakers," Transactions of China Electrotechnical Society, vol. 13, no. 5, pp. 1-8, 1998.

[13] W. Xin, G. Chuang-xin, and C. Yi-jia, "A new fault diagnosis approach of power system based on Bayesian network and temporal order information," Proceedings of the CSEE, vol. 25, no. 13, pp. 14-18, 2005.

[14] L. Tang, H.-B. Sun, and B.-M. Zhang, "Online fault diagnosis for power system based on information theory," Proceedings of the CSEE, vol. 23, no. 7, pp. 5-11, 2003. 


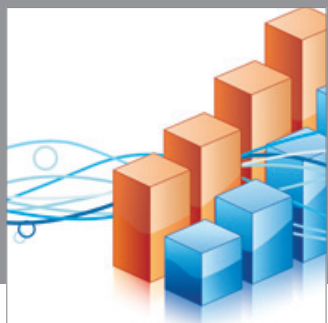

Advances in

Operations Research

mansans

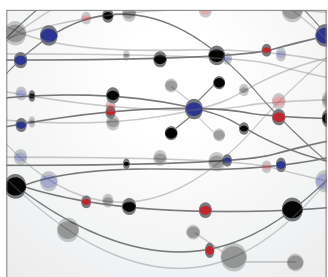

The Scientific World Journal
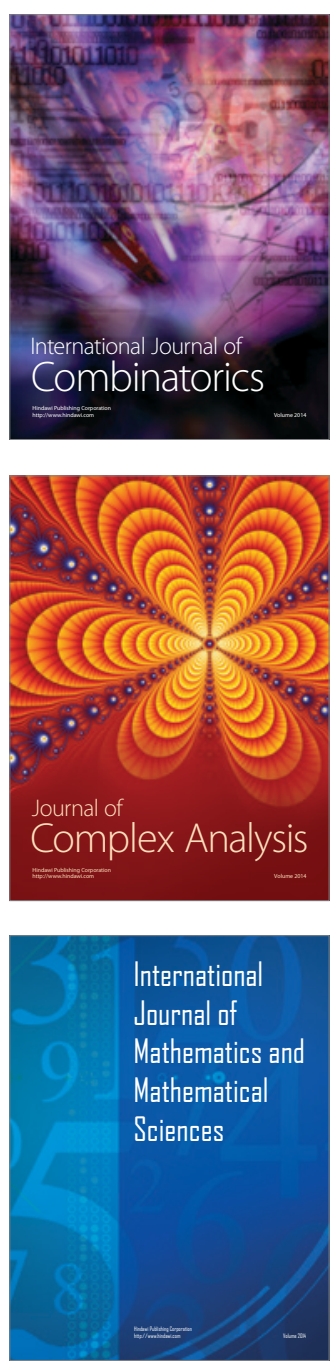
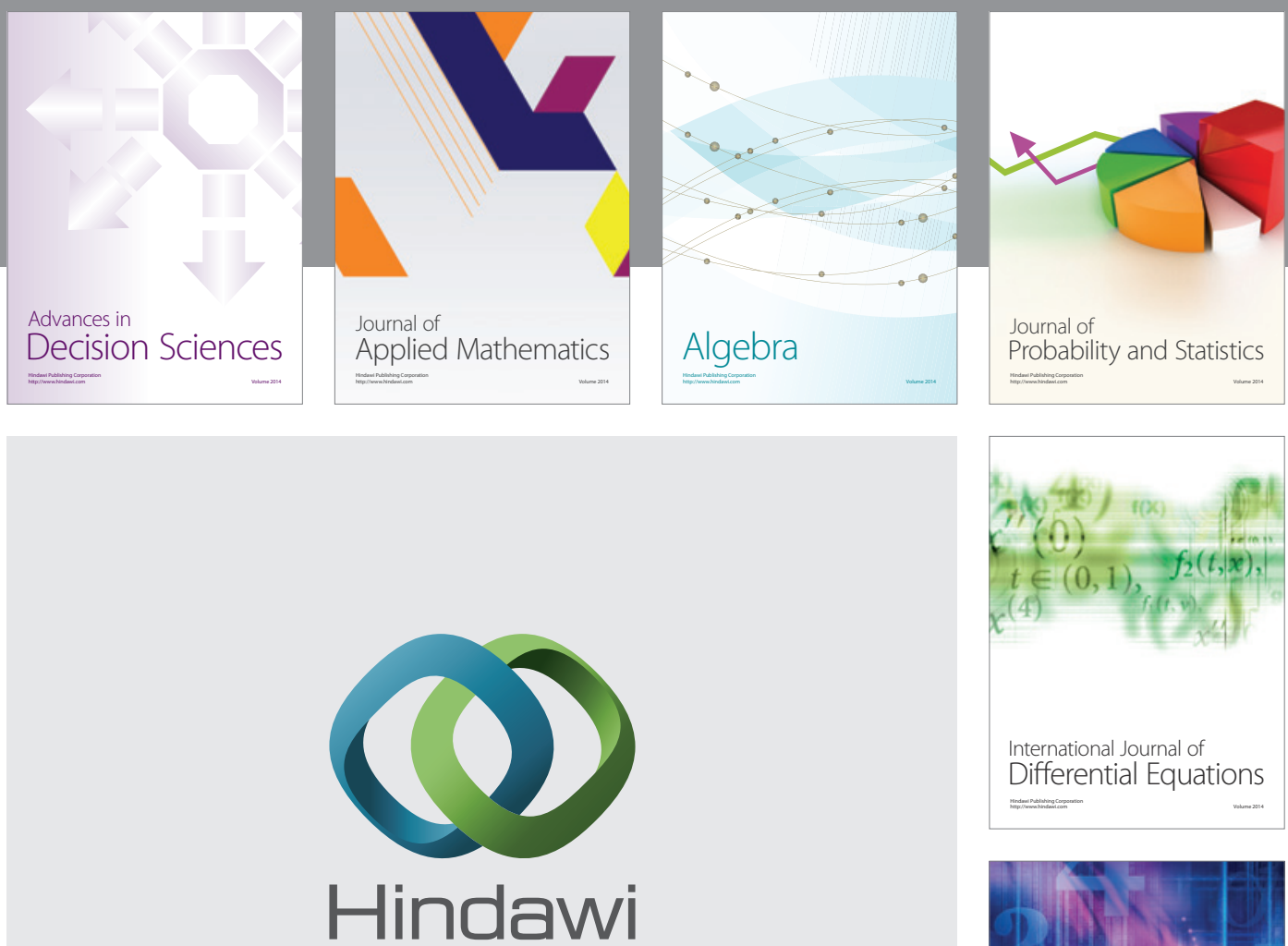

Submit your manuscripts at http://www.hindawi.com
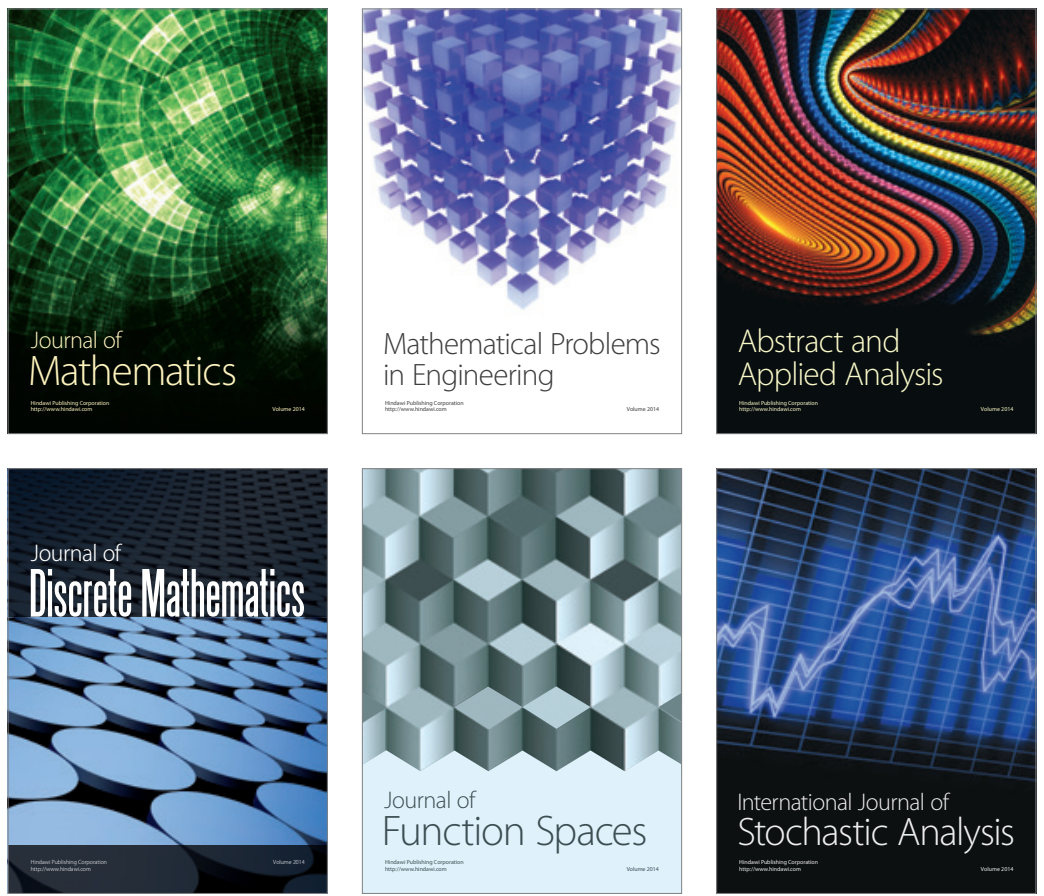

Journal of

Function Spaces

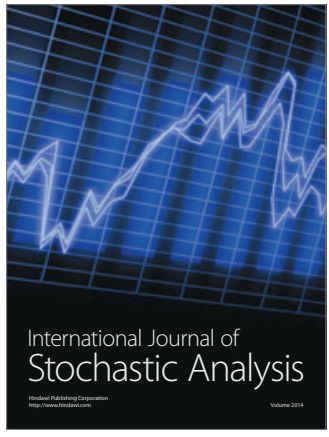

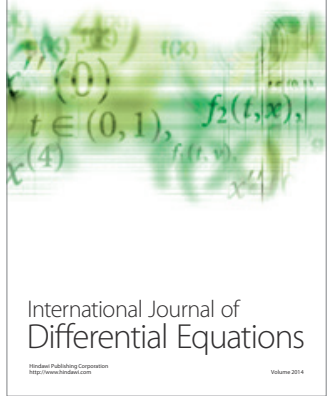
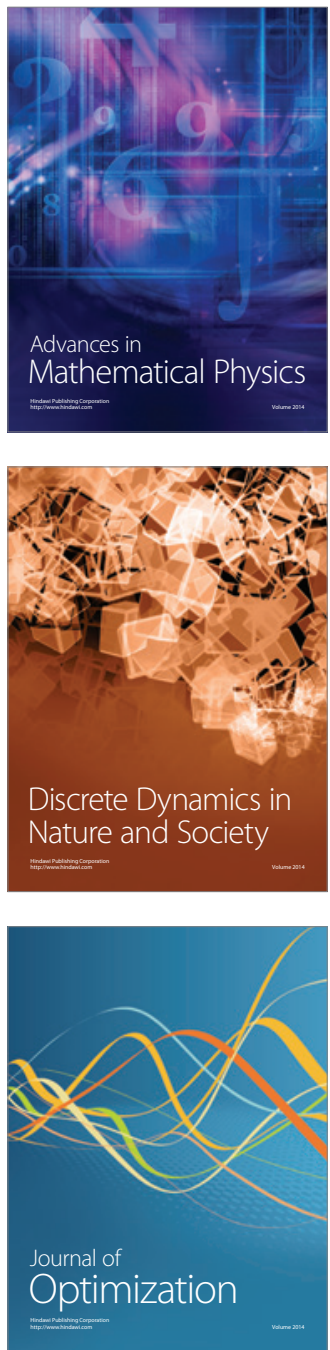